\title{
Country of Potential Disease Exposure
}

National Cancer Institute

\section{Source}

National Cancer Institute. Country of Potential Disease Exposure. NCI Thesaurus. Code C102612.

System of classification based on the nation in which an individual was exposed to a disease, regardless of the nation in which he/she currently resides. 